\title{
最良モデル探索のための変分ベイズ学習
}

\section{Variational Bayesian Learning for Optimal Model Search}

\author{
$\underset{\text { 上aonori Ueda }}{\text { 上蓚功 }}$
}

\author{
$\mathrm{NTT}$ コミュニケーション科学基礎研究所 \\ NTT Communication Science Laboratories \\ ueda@cslab.kecl.ntt.co.jp, http://www.kecl.ntt.co.jp/as/members/ueda/index-j.html
}

keywords: Bayesian learning, variational approximation, model search, split and merge operations, local optima problem.

\section{Summary}

When learning a nonlinear model, we suffer from two difficulties in practice: (1) the local optima, and (2) appropriate model complexity determination problems. As for (1), I recently proposed the split and merge Expectation Maximization (SMEM) algorithm within the framework of the maximum likelihood by simulataneously spliting and merging model components, but the model complexity was fixed there. To overcome these problems, I first formally derive an objective function that can optimize a model over parameter and structure distributions simultaneously based on the variational Bayesian approach. Then, I device a Bayesian SMEM algorithm to efficiently optimize the objective function. With the proposed algorithm, we can find the optimal model structure while avoiding being trapped in poor local maxima. I apply the proposed method to the learning of a mixture of experts model and show the usefulness of the method.

\section{1.はじめに}

統計的学習の目的は, 観測データの背後にある生成モ デルの推定である.近年，構造が複雑なデータを対象に， 樣々な非線形モデルが適用されている.しかしながら , 非 線形モデルを学習する際，実用上，(1) 局所最適性 (local optimality)，および，(2) モデルの複雑さ (model complexity)の決定, の問題に悩まされる .

(1) は学習アルゴリズムが所望の大域的最適解に収束 せず, 初期解の近傍の局所最適解に収束するという問題 である . また (2) は, 例えば 3 層ニューラルネットワー クの場合, 中間ユニット数の決定, また, 混合モデルで は混合要素数の決定など, 非線形モデルの構造決定問題 を指す．モデルの複雑さを学習タスクの複雑さに応じて 適切に定めないと汎化能力 (未学習データに対する予測 能力) の低下を招く .

筆者は先に，(1) の問題に対処すべく，混合モデルを 対象に最尤推定法の一般的数值解法である EM アルゴリ ズム [Dempster 77] に，モデルの同時併合分割による局 所解からの脱出とより尤度値の高い解への誘導を图る併 合分割操作を導入した併合分割操作付き $\mathrm{EM}$ (Split and Merge EM: SMEM) アルゴリズムを考案し [Ueda 99a]， 樣々な応用での有効性を示した [Ueda 99b, Ueda 00] .

しかしながら，SMEM アルゴリズムは (2) の問題には 対処していなかった . 兴の理由は, 最尤推定では, 一般に モデルパラメータの次元の増加と共に尤度が単調増加す
るため, 尤度を基準にして併合分割操作で最適なモデル を探索することができないことに因る，乥こで，SMEM アルゴリズムでは, モデルの併合と分割を同時に行い，モ デルの複雑さ (混合数) を固定していた .

これに対し，尤度值ではなく AIC, MDL 等の情報量 基準 [Akaike 73, Rissanen 87] を用いたモデル探索も考 えられるが , 多くの非線形モデルの場合 , 情報量基準の 導出で仮定される最尤推定量の漸近正規性が成り立たな いため，これら情報量基準に基づくモデル探索は実用上 うまく作用しない .

本論文では, SMEM アルゴリズムの “モデルの併合分 割操作”の考え方をベイズ学習の近似法である変分ベイ ズ学習 (variational Bayesian learning) [Waterhouse 95] に導入し , 非線形モデルの上記 (1),(2) の問題を同時解 決する新たな学習法 (最良モデル探索のための变分ベイ ズ学習法) を提案し，混合回帰モデルへの適用実験によ り手法の有効性を示す.

変分ベイズ学習法は後述するように, ベイズ学習の核 となる事後分布の一近似法であるが, ラプラス近似法 [MacKay 92] より近似精度が高く, また, マルコフ連 鎖モンテカルロ (MCMC) 法 [Gamerman 97] より遥か に効率的な手法として近年注目されている。

変分ベイズ学習は, 当初, 汎化性能の観点で最尤法に 対する優位性を示していた [Waterhouse 95] が，上記 (1),(2)の問題は全く取り扱われていなかった . 最近 , Attias は, モデルの複雑さも確率変数として取り扱うこと 
により上記 (2) の一解決法を示している [Attias 99] が， (1)の問題は取り扱っていない . また , モデルのパラメー タ学習とモデルの複雑さの決定が 2 段階に実行され，候 補モデルの中から最良なモデルを選ぶという“モデル選 択的”手法であった 。

最近, Ghahramani らは混合因子分析モデルを対象と して，変分ベイズ学習法の枠組みでモデルの削除と追加 に基づくモデル探索法を提案している [Zoubin 00] . しか しながら，弚こではモデル探索のアイデアに留まり，乥 の正当性に関する根拠は示されていなかった 。

これに対し本論文では，一般の非線形モデルを対象に， 変分ベイズ学習においてモデルのパラメータ学習とモデ ルの複雑さの決定が, 同一の評価関数の最小化問題とし て定式化できることを示す．これにより，モデル探索学 習法という新たな枠組みの正当性を保証する。

以下の本文では，2. 節でベイズ学習の概要を述べ, 3. 節でベイズ学習の近似法である変分ベイズ法, および光 の問題点について述べる . 次いで , 4. 節で光の問題解決 法を提案し，5. 節で適用実験結果を示す。

\section{2. ベイズ学習}

\section{$2 \cdot 1$ 予測事後分布}

今, モデルの複雑さの指標 $m$ とモデルパラメータ $\theta$ で 規定されるパラメトリックな確率分布 (確率モデル)のク ラスを $\mathcal{H}_{m}=\{p(\cdot \mid \theta, m)\}$ とし，これを仮説空間と呼ぶ: こととする

統計的学習のゴールは，観測データ $D=\left\{d_{i}\right\}_{i=1}^{N}$ に基 づいて仮説空間上で真のモデルを最良近似する仮説を“ 探索”することと言える.最尤学習では弚の良さの基準 として尤度 (対数尤度) を用いる. 即ち, 最尤学習での最 適仮説のモデルパラメータは次式で与えられる .

$$
\theta^{*}=\arg \max _{\theta}\{\log p(D \mid \theta, m)\}
$$

尚 , 混合分布モデルのように非観測変数 $(Z$ とする) を取 り扱う場合は, $p(D \mid \theta, m)=\sum_{Z} p(D, Z \mid \theta, m)$ とすれ ば良い。

一方, ベイズ学習では尤度に加えてパラメータ $\theta$ の事 前分布 $p(\theta \mid m)$ をも考慮する . 即ち, 最尤学習の樣に一つ の仮説 $p(D \mid \hat{\theta}, m)$ を求めるのではなく，未知データ $d_{N+1}$ に対し， $D$ が与えられた下での $\theta$ の事後分布 $p(\theta \mid D, m)$ で仮説 $p\left(d_{N+1} \mid \theta, m\right)$ を重み付き平均した “事後の予測分 布” $p\left(d_{N+1} \mid D, m\right)$ を次式で求め $d_{N+1}$ についての確率的 な言明を行う .

$$
p\left(d_{N+1} \mid D, m\right)=\int p\left(d_{N+1} \mid \theta, m\right) p(\theta \mid D, m) d \theta(1)
$$

従って，一般に，ベイズ学習は最尤学習に比べ過学習が 抑制される.更に,ベイズ学習ではモデル指標 $m$ も確率
変数として取り扱える. $m$ の事前分布 $P(m)$ も考慮する と, 式 (1) は次式のように書き換えられる.

$$
p\left(d_{N+1} \mid D\right)=\sum_{m} \int p\left(d_{N+1} \mid \theta, m\right) p(\theta, m \mid D) d \theta(2)
$$

\section{$2 \cdot 2$ ベイズ学習の実用上の問題点}

上記事後予測分布は特殊な場合を除き解析的に求める ことが困難で何らかの近似法を援用して求める. 弚の一 近似法としてラプラス近似法 [MacKay 92] がある . ラ プラス近似法では事後分布をガウス関数近似し上記積分 を解析的に求める手法である。しかしながら，この近似 は無限個のデータ数を前提 (漸近正規性) にした近似であ り，現実問題での近似精度に問題がある。

より正確な近似解法としてマルコフ連鎖モンテカルロ (MCMC) 法がある . 通常のモンテカルロ法との相違点 は, $x$ 空間全てを評価するのではなく,$p(x)$ を近似する 有限個の $\left\{x_{t}\right\}$ をサンプリングという形式で “生成”する 点にある .サンプリングの具体的手法としてメトロポリ ス法 , Gibbs サンプリング法が著名である [Gamerman 97] .

尚，従来 MCMCではモデルパラメータの次元 (モデル の複雑さ) は固定されていたが, 最近, "reversible jump MCMC 法” と呼ばれるパラメータ次元を変更しながらサ ンプリングを実行する手法か提案されている [Richardson 97].しかしながら , これら MCMC 法はサンプリングに 膨大な時間を要し，また，収束判定も一般には容易では ないという問題がある . 次節では, ラプラス近似よりも 近似精度が高く，MCMCに比へ遥かに効率的な，Bayes 学習の第三のアプローチである変分ベイズ学習法につい て述べる。

\section{3. 変分ベイズ学習}

\section{$3 \cdot 1$ 変 分 近 似}

ベイズ学習では,前述した樣に全ての未知量 $Z, \theta, m$ を 確率変数として取り扱う. 乥こで,これら全ての未知量 を周辺化した次式の周辺尤度を考える。

$$
\begin{aligned}
\mathcal{L}(D) & =\log p(D) \\
& =\log \sum_{m} \sum_{Z} \int p(D, Z, \theta, m) d \theta
\end{aligned}
$$

ここに, $Z$ は潜在变数 (非観測データ) を表す．

全ての確率変数の結合分布 $p(D, Z, \theta, m)$ は

$$
p(D, Z, \theta, m)=p(D, Z \mid m) p(\theta \mid m) P(m)
$$

と分解できる . 式 (4) の右辺第 1 項はモデル指標が与え られた下での完全データ尤度に，第 2 項はモデル指標が 与えられた時のパラメータ $\theta$ の事前分布, 乥して, 第 3 項はモデル指標の事前分布に, 各々対応している. 
ここで, 新たな分布 $Q$ を導入し, 対数関数に対する Jensen の不等式を適用することにより以下の樣に $\mathcal{L}(D)$ の下限值 $\mathcal{F}[Q]$ を得る .

$$
\begin{aligned}
\mathcal{L}(D) & =\log \sum_{m} \sum_{Z} \int Q(Z, \theta, m) \frac{p(D, Z, \theta, m)}{Q(Z, \theta, m \mid D)} d \theta \\
& =\log \left\langle\frac{p(D, Z, \theta, m)}{Q(Z, \theta, m \mid D)}\right\rangle_{Q(Z, \theta, m)} \\
& \geq\left\langle\log \frac{p(D, Z, \theta, m)}{Q(Z, \theta, m \mid D)}\right\rangle_{Q(Z, \theta, m)} \\
& =\sum_{m} \sum_{Z} \int Q(Z, \theta, m) \log \frac{p(D, Z, \theta, m)}{Q(Z, \theta, m \mid D)} d \theta \\
& \equiv \mathcal{F}[Q]
\end{aligned}
$$

但し，表記 $\langle f(x)\rangle_{p(x)}$ は $f(x)$ の $p(x)$ に関する期待値:

$$
\langle f(x)\rangle_{p(x)}=\int f(x) p(x) d x
$$

\section{を表すものとする .}

$\mathcal{F}[Q]$ は $Q$ を変関数とする汎関数であることに注意 . ある関数の下限値 (もしくは上限值) を定数ではなく関数 で抑える近似法を一般に変分近似 (variational approximation) と呼ぶ [Jordan 97] . 上記では, $\mathcal{F}[Q]$ か㳔数周 辺尤度 $\mathcal{L}$ の下限值となっている。

$\mathcal{L}$ と $\mathcal{F}$ の間には次式に示す関係式が成り立つ．

$$
\mathcal{L}(D)=\mathcal{F}[Q]+\operatorname{KL}(Q(Z, \theta, m \mid D) \| p(Z, \theta \mid D))(6)
$$

ここに, 右辺第 2 項は分布 $Q(Z, \theta, m \mid D)$ と $p(Z, \theta \mid D)$ と の Kullback-Leibler 距離である .

式 (6) で $\mathcal{L}$ が $D$ のみに依存する定数であることに注 意すると，下限值を最大化すべく, $\mathcal{F}[Q]$ を $Q$ に関して 最大化することは, $Q$ と真の事後分布 $p(\cdot \mid D)$ との KL 情報量を最小化することと等価である . 換言すれば， $\mathcal{F}$ を最大化する分布 $Q$ は真の事後分布の最良の近似となっ ている. 真の事後分布を変分近似する事後分布であるこ とから, $Q$ は変分事後分布と呼ばれる ${ }^{* 1}$.

上記は [Waterhouse 95] らの定式化であるが，これは 最尤学習における変分近似 [Saul 96] をベイズ拡張した ものである. $Q$ として, 通常, 次式の樣に各末知変量毎 に分解した形 (factorization form) を仮定するが, 各分 布族は任意で良い。

$$
Q(Z, \theta, m)=Q(Z \mid m) Q(\theta \mid m) Q(m)
$$

式 (7) の制約された形で真の事後分布を推定するため一 般には真の分布に一致しないが , 全パラメータの同時事 後分布を単一の正規分布で近似するラプラス近似法に比 べれば，遥かに近似精度が高いと言える。

\footnotetext{
$* 1 \quad Q$ は事後分布故 , 本来は $Q(\cdot \mid m, D)$ と書くべきであるが表 記を簡単にする為，D 省略している。
}

\section{$3 \cdot 2$ 最適事後分布とモデル選択}

モデル指標 $m$ が与えられた下での $\theta$ の最適変分事後分 布 $Q(\theta \mid m)$ は,制約条件 $\int Q(\theta \mid m) d \theta=1$ の下で $\mathcal{F}[Q]$ を $Q$ に関して最大化することにより容易に得られる [Attias 99] .

$$
\begin{aligned}
Q(\theta \mid m)=\frac{1}{C_{\theta}} \exp \{ & \langle\log p(D, Z \mid \theta, m)\rangle_{Q(Z \mid m)} \\
& +\log p(\theta \mid m)\}
\end{aligned}
$$

但し, $C_{\theta}$ は $\int Q(\theta \mid m) d \theta=1$ となるための規格化定数で ある. 同樣に，

$$
Q(Z \mid m)=\frac{1}{C_{Z}} \exp \left\{\langle\log p(D, Z \mid \theta, m)\rangle_{Q(\theta \mid m)}\right\}
$$

式 (8),(9)より明らかな樣に, $Q(\theta \mid m)$ と $Q(Z \mid m)$ は相 互に依存関係にあり閉形式て解くことはできず逐次解法 により求める. 即ち, 第 $t$ 反復での事後分布の推定値を 各々 $Q(Z \mid m)^{(t)}$ の $Q(\theta \mid m)^{(t)}$ とすると, 第 $t+1$ 反復で の推定值は各々以下で計算すれば良い。

$$
\begin{gathered}
Q(Z \mid m)^{(t+1)}= \\
\frac{1}{C_{Z}} \exp \left\{\langle\log p(D, Z \mid \theta, m)\rangle_{Q(\theta \mid m)^{(t)}}\right\} \\
\begin{aligned}
Q(\theta \mid m)^{(t+1)}= & \frac{1}{C_{\theta}} \exp \left\{\langle\log p(D, Z \mid \theta, m)\rangle_{Q(Z \mid m)^{(t+1)}}\right. \\
& +\log p(\theta \mid \varphi, m)\}
\end{aligned}
\end{gathered}
$$

式 (10),(11) を反復して実行することにより局所最適事 後分布 $Q(Z \mid m)^{*}, Q(\theta \mid m)^{*}$ を得る .

但し, 上記は非線形最適化法の coordinate ascent 法 と同樣な反復写像法であるが, 変分近似問題に反復写像 法を用いた場合，収束性に関する理論的保証はない，し かしながら，文献 [Attias 99][Zoubin 00] および後述す る筆者の実験に関する限り，(局所) 最適解への収束を確 認している，収束性に関する厳密な議論は別途検討課題 と言える

次いで, モデル指標 $m$ の最適事後分布は $\mathcal{F} の Q(m)$ に関する最大化より解析的に求まる.

$$
\begin{aligned}
Q(m)^{*} & =\frac{1}{C_{m}} \exp \left\{\left\langle\log \frac{p(D, Z \mid \theta, m)}{Q(Z \mid m)^{*}}\right\rangle_{Q(Z, \theta \mid m)^{*}}\right. \\
& \left.+\left\langle\log \frac{p(\theta \mid \varphi, m)}{Q(\theta \mid m)^{*}}\right\rangle_{Q(\theta \mid m)^{*}}+\log P(m)\right\}
\end{aligned}
$$

$Q(m)^{*}$ を最大にする $m$ が事後分布最大化 (Maximum a posteriori Probability: MAP) の観点で最適なモデル指 標となる [Attias 99] .

ベイズ推定の場合，式 (2)に示した樣に，本来は全て の可能なモデルのアンサンブルとして予測分布を求める . しかしながら，害用的にはある最良なモデルのみに着目 して単一のモデルを選択することも可能である.$Q(m)$ が単峰でかつ鋭いピークを持つ場合には十分な近似が得 
られることが期待される . 次節で提案するモデル探索法 は, この最良単一モデル選択の考え方に基づく.但し，単 にモデルを選択するのではなく，弚の過程で 1. 節で述べ た (1) の局所最適性の問題も同時に解決する新たな変分 ベイズ学習法の提案である .

\section{4. モデル探索学習}

\section{$4 \cdot 1$ モ デル探索}

式 $(5)$ の $\mathcal{F}[Q]$ において， $Q(m)$ を含まない項をまと めて $\mathcal{F}_{m}$ と書くと次式を得る .

$$
\mathcal{F}[Q]=\left\langle\mathcal{F}_{m}\right\rangle_{Q(m)}-\mathrm{KL}(Q(m) \| P(m))
$$

ここで, $\mathcal{F}_{m}$ は $Q(m)$ には依存しないが， $m$ に依存する ことに注意 . $\mathcal{F}_{m}$ は次式で与えられる .

$$
\mathcal{F}_{m}=\left\langle\log \frac{p(D, Z \mid \theta, m) p(\theta \mid \varphi, m)}{Q(Z \mid m) Q(\theta \mid m)}\right\rangle_{Q(Z, \theta \mid m)}
$$

式 (13) の右辺第 1 項の $\mathcal{F}_{m}$ は， $Q(Z \mid m), Q(\theta \mid m)$ に 依存する . 従って 3.2 節で述べた $\mathcal{F}[Q]$ の最大化は以下 の 2 ステップの最大化と等価である .

[従来の変分ベイズ学習アルゴリズム]

Step 1: 各 $m \in \mathcal{M}$ に対し， $Q(Z \mid m)^{(0)}, Q(\theta \mid m)^{(0)}$ を設定し， $t \leftarrow 0$ とし，以下を収束するまで実行 .

$$
\begin{aligned}
& Q(Z \mid m)^{(t+1)}= \\
& \quad \arg \max _{Q(Z \mid m)} \mathcal{F}_{m}\left[Q(Z \mid m), Q(\theta \mid m)^{(t)}\right] \\
& Q(\theta \mid m)^{(t+1)}= \\
& \quad \arg \max _{Q(\theta \mid m)} \mathcal{F}_{m}\left[Q(Z \mid m)^{(t+1)}, Q(\theta \mid m)\right] \\
& t \leftarrow t+1
\end{aligned}
$$

Step 2: 各 $m \in \mathcal{M}$ に対し, $\mathcal{F}_{m}$ を $m$ に関し最大化す る. (M は候補モデル指標集合を表す . $)$

ここで, $\mathcal{F}_{m}^{*}$ をStep 1 で得られた $\mathcal{F}_{m}$ の最適値を表す ものとすると式 (13)より次式を得る .

$$
\mathcal{F}[Q]=\left\langle\mathcal{F}_{m}^{*}\right\rangle_{Q(m)}-\mathrm{KL}(Q(m) \| P(m))
$$

従って , Step 2 は, $\sum_{m} Q(m)=1$ の下で $Q(m)$ に関す る式 (15) の最大化により

$$
Q(m)^{*}=\frac{P(m) e^{\mathcal{F}_{m}^{*}}}{\sum_{l=1}^{M} P(l) e^{\mathcal{F}_{l}^{*}}}
$$

と求まる.式 (16) が式 (12) と等価であることは容易に 確認できる .

ここで式 (16) を注意深く見ると, 分母は $m$ に依存し ないので $Q(m)$ の $m$ に関する最大化は $P(m) e^{\mathcal{F}_{m}}$ の最 大化と等価であることが分かる. 簡単のため $m$ の事前分
布を一樣分布 $P(m)=1 / M$ とすると, $Q(m)$ の最大化 は単純に $\mathcal{F}_{m}$ の最大化となる．換言すれば， $Q(m)$ を最 大化する $m$ は $\mathcal{F}_{m}$ を最大化する $m$ に他ならない .

従って,

$$
\mathcal{F}_{m}^{(t)}=\left\langle\log \frac{p(D, Z \mid \theta, m) p(\theta \mid \varphi, m)}{Q(Z \mid m)^{(t)} Q(\theta \mid m)^{(t)}}\right\rangle_{Q(Z, \theta \mid m)^{(t)}}
$$

および，

$$
Q(m)^{(t)}=\frac{P(m) e^{\mathcal{F}_{m}^{(t)}}}{\sum_{l=1}^{M} P(l) e^{\mathcal{F}_{l}^{(t)}}}
$$

とし, 更に, $P(m)=1 / M$ とすると, 次の単調性が成り 立つ。

$$
\mathcal{F}_{m^{\prime}}^{(t)} \geq \mathcal{F}_{m}^{(t)} \Rightarrow Q\left(m^{\prime}\right)^{(t)} \geq Q(m)^{(t)}
$$

これは $\mathcal{F}_{m}$ を $Q(\theta \mid m), Q(Z \mid m)$ のみならず $m$ に関して も同時に最大化することにより，式 (18) を計算すること なく最適なモデル指標 $m$ が同時に求まることを意味する.

つまり, $F[Q]$ ではなく $\mathcal{F}_{m}$ を目的関数として $Q(Z \mid m)$, $Q(\theta \mid m)$ および $m$ に関して同時に最大化することにより 事後分布最大化 (Maximum a posteriori Probability: MAP) の観点で最適なモデルパラメータおよび最適なモ デル指標が次式の樣に得られるわけである.

$$
\left\{\begin{array}{l}
\theta_{\mathrm{MAP}}=\arg \max _{\theta}\left\{Q(\theta \mid m)^{*}\right\} \\
m_{\mathrm{MAP}}=\arg \max _{m}\left\{Q(m)^{*}\right\}
\end{array}\right.
$$

$\theta_{\mathrm{MAP}}$ および $m_{\mathrm{MAP}}$ が得られれば，式 (2)に示した未知 データ $d_{N+1}$ に対する予測分布は次式の樣に近似的に求 まる .

$$
p\left(d_{N+1} \mid D\right) \simeq p\left(d_{N+1} \mid \theta_{\mathrm{MAP}}, m_{\mathrm{MAP}}\right)
$$

\section{$4 \cdot 2$ 併合分割操作付き変分ベイズ学習}

4.1 節では, 同一の目的関数で $\theta$ および $m$ の最適值が 同時に学習可能であることを示した . 本節では光の実現 アルゴリズムとして併合分割操作付き変分ベイズ学習ア ルゴリズムを提案する .

今，仮説空間 $\mathcal{H}_{i}$ が $i$ に関する直和として

$$
\mathcal{H}=\cup_{i=1}^{m} \mathcal{H}_{i}
$$

で与えられる場合を考える .一般の混合モデルでは常に 成立する .この場合，局所解の大半はあるデータ領域に 過剩数のモデルか割り当てられ，かつ，あるデータ領域 に過少数のモデルか割り当てられた状況に相当する. 実 際，4.1 節の Step 1 の $\mathcal{F}_{m}$ の最大化 (式 (10),(11) の逐 次増大化)では, 適切な初期値を設定しない限り, 上記 のような不均衡なモデル配置 (低品質な局所解) に収束し てしまう。

このモデル配置の不均衡を解消し，より良いモデル配 置を実現するために, 最尤学習の枠組みで提案したモデ 
ルの併合分割操作 [Ueda 99a] を変分ベイズ学習に導入 する.但し，ここではモデル指標 $m$ も同時に最適化する という点で更に拡張している.

式 (21) が成立する場合, $\mathcal{F}_{m}$ は次式の樣に, 各要素モ デルの目的関数の直和で書き表せる .

$$
\mathcal{F}_{m}=\sum_{i=1}^{m} \mathcal{F}_{(i)}
$$

$\mathcal{F}_{(i)}$ は混合モデルの第 $i$ 要素モデルの目的関数に対応す る.今，ある $m$ に対し，式 (10),(11) により得た事後分 布 (局所最適解) を $Q^{*}$, 光の時の $\mathcal{F}_{m}$ の值を $\mathcal{F}_{m}^{*}$ と書く こととすると, 式 (22) は更に次式の樣に書ける .

$$
\mathcal{F}_{m}^{*}=\mathcal{F}_{(i)}^{*}+\mathcal{F}_{(j)}^{*}+\mathcal{F}_{(k)}^{*}+\sum_{u, u \neq i, j, k} \mathcal{F}_{(u)}^{*}
$$

この時, 式 (23)の右辺の最初の3 項のみに着目し, 要素 モデル $i$ と要素モデル $j$ とを新たな要素モデル $i^{\prime}$ として 併合し, 要素モデル $k$ を二つの要素モデル $j^{\prime}$ と $k^{\prime}$ とに 分割することにより， $\mathcal{F}_{m}$ 值の更なる増大を試みる。

前述した樣に, 最尤学習では $m$ を増加 (減少)させる と一般に尤度か増加 (減少)するので, 例えば分割のみを 行うと, 分割と再学習により局所解から脱出してより良 い解に到達して尤度か増加したのか, 単に $m$ が増加した ことで尤度が増加したかのかの識別か困難となる．弚れ 故，SMEM アルゴリズムでは $m$ を固定すべく，併合と 分割を同時に行っていた。

一方, 4.1 節で述べた樣に, 変分ベイズ学習では目的関 数 $\mathcal{F}_{m}$ を用いてパラメータとモデルの複雑さの最適化が 同時実行できる. 即ち, $m$ の増加と共に $\mathcal{F}_{m}$ 值は単調増 加せず, 最適な $m$ の值に対し最大值をとる. 乥こで, 同 時併合分割操作だけでなく，“併合操作のみ”，あるいは,“" 分割操作のみ”，も試みる. 明らかに“併合 (分割) 操作 のみ”は $m$ を 1 だけ増加 (減少)させることを意味する.

従って，これら 3 種類の操作を実行し， $\mathcal{F}_{m}$ を増大さ せることにより, 局所最適性の問題と最適なモデルの複 杂隹さの決定の問題が同時解決可能となる. 以上が変分べ イズ学習の枠組みに併合分割操作を導入した併合分割操 作付き変分ベイズ学習アルゴリズムの概要である . アル ゴリズムの詳細は以下の通りである .

[最良モデル探索のための変分ベイズ学習アルゴリズム] Step 1: $m$ および事後分布の初期值を設定し, 式 (16),(17) に基づく通常の変分ベイズ学習を実行する . 収束した時の事後分布の值を $Q(\theta \mid m)^{*}, Q(Z \mid m)^{*}$ と し $, F^{*} \leftarrow \mathcal{F}_{m}^{*}, m^{*} \leftarrow m$ とする.

Step 2: 現在の事後分布に基づき併合分割候補 $(C$ 個) をソートする .

Step 3: 以下の (3-1),(3-2),(3-3) を各々実行する .

(3-1): 併合: $C$ 個の併合候補を順に, 目的関数の值が $F^{*}$ より大きくなるまで併合操作のみによる探 索を行う. 谷の時の目的関数の值を $F_{1}^{* *}$ とする.
(3-2)：併合分割： $C$ 個の併合分割候補を順に，目的 関数が $F^{*}$ を上回るまで同時併合分割操作によ る探索を行う. 弚の時の目的関数の值を $F_{2}^{* *}$ と する .

(3-3): 分割: $C$ 個の分割候補を順に, 目的関数が $F^{*}$ を上回るまで分割操作のみによる探索を行う.乥 の時の目的関数の值を $F_{3}^{* *}$ とする.

Step 4: Step 3で $F^{*}$ を上回る候補がなければアルゴ リズムを終了.さもなくば，

$$
F^{*} \leftarrow \max \left\{F_{1}^{* *}, F_{2}^{* *}, F_{3}^{* *}\right\}
$$

とし， $F^{*}=F_{1}^{* *} な ら(3-1)$ の探索結果を採用し， $m^{*} \leftarrow m^{*}-1$ として Step 2 へ. $F^{*}=F_{2}^{* *}$ なら (3-2) の探索結果を採用し, Step 2 へ. $F^{*}=F_{3}^{* *}$ なら (3-3) の探索結果を採用し, $m^{*} \leftarrow m^{*}+1$ とし Step 2 へ.

上記アルゴリズムの Step 3 の (3-1),(3-2),(3-3) の各々 は $m$ を固定した下で, $Q(Z, \theta \mid m)$ の局所解からの脱出と より良い解への誘導を行う. 乥して，最適モデル選択の 観点で, この 3 通りのモデルの複雑さから最良のものを Step 4 で選択する .これら一連の処理を反復することに より，局所解を回避しながら最適モデルを探索すること ができる.

Step 2 での併合分割候補基準，および Step 3 での併 合 , 分割直後の初期化および再学習は SMEM アルゴリ ズムの時と同樣に行えるので省略する (文献 [Ueda 00] 参 照) . Step 3 はいわゆる greedy search 故, 上記アルゴリ ズムは $\mathcal{F}_{m}$ のより良い極大値の探索であり，大域的最大 值が得られる理論的保証はない．しかしながら， $\mathcal{F}_{m}$ の 単調増加性は保証される為, より良い極大值の探索か俲 率良く実現できる。

\section{5. 混合回帰 $(\mathrm{MoE})$ モデルへの適用}

本節では, 本学習法の有効性を検証すべく, ニューラル ネットの代表モデルの一つである混合回帰モデル (Mixture of Experts: MoE)[Jacobs 91] による回帰問題 (関 数近似問題) を対象に, 本学習法を適用した結果につい て述べる。

\section{$5 \cdot 1 \quad M o E$ の確率モデル}

$\mathrm{MoE}$ は,$m$ 個の回帰モデルと入カデータを個々の回 帰モデルに割り当てる役目を担うゲート関数から成る混 合回帰モデルである . 個々の回帰モデルは “expert” , 混 合回帰モデルは “mixture of experts” と通常呼ばれてい る. 直観的には, 関数近似問題を単一の関数で回帰する のでなく,データ領域を分割し, 単純な関数近似問題に 分割して解くモデルである.但し, 領域分割は関数近似 
と独立して実行されるのではなく，関数近似と同時に実 行されるという点で柔軟なモデルとなっている．

$\mathrm{MoE}$ に対する変分ベイズ学習は既に提案されている [Waterhouse 95] が , 光こでは 1. 節の問題 (1) および (2) は全く取り扱われていない，また，本節では，MoE の確 率モデルとして入出力の同時分布を用いているため, 文 献 [Waterhouse 95] と異なり全ての変分事後分布を解析 的に導出している．これらの点で本節で述べる $\mathrm{MoE} の$ 変分ベイズ学習は文献 [Waterhouse 95] の成果をより発 展させていると言える

$\boldsymbol{x} \in \mathcal{R}^{d}$ を入力 , $f_{i}\left(\boldsymbol{x}, \theta_{i}\right) \in \mathcal{R}$ を入力 $\boldsymbol{x}$ に対応するモ デル $i$ の出力 ${ }^{2}$ を表すものとすると, $\operatorname{MoE}$ の入力 $\boldsymbol{x}$ に 対する出力 $y$ は次式で与えられる.

$$
y=\sum_{i=1}^{m} G_{i}(\boldsymbol{x} \mid \Phi) f_{i}\left(\boldsymbol{x}, \theta_{i}\right)
$$

文献 [Waterhouse 95] 同樣, 各要素回帰モデル (expert) として線形モデルを採用した .

$$
f_{i}\left(\boldsymbol{x}, \boldsymbol{w}_{i}\right)=\boldsymbol{w}_{i}^{T} \boldsymbol{x}^{\prime}, i=1, \ldots, m
$$

$\boldsymbol{x}^{\prime}=\left(\boldsymbol{x}^{T} 1\right)^{T}, \boldsymbol{w}_{i}=\left(w_{i d}, \ldots, w_{i 1}, w_{i 0}\right)^{T} \in \mathcal{R}^{d+1}$ とし,$w_{i 0}$ はバイアスに相当する .

ここに, $G_{i} \in \mathcal{R}$ はゲート関数の第 $i$ 出力で, 通常, softmax 関数が通常用いられるが，ここでは, 正規化ガウス 関数を用いた $[\mathrm{Xu} \mathrm{94]}$.

$$
G_{i}(\boldsymbol{x} \mid \Phi)=\frac{\varphi_{i} \mathcal{N}\left(\boldsymbol{x} \mid \boldsymbol{\mu}_{i}, \boldsymbol{S}_{i}^{-1}\right)}{\sum_{j=1}^{m} \varphi_{j} \mathcal{N}\left(\boldsymbol{x} \mid \boldsymbol{\mu}_{j}, \boldsymbol{S}_{j}^{-1}\right)}
$$

但し， $\varphi_{i}$ は混合比 $\left(\varphi_{i} \geq 0\right.$ かつ $\left.\sum_{i=1}^{m} \varphi_{i}=1\right)$ で, 表記 $\mathcal{N}\left(\boldsymbol{x} \mid \boldsymbol{\mu}, \boldsymbol{S}^{-1}\right)$ は平均ベクトル $\boldsymbol{\mu}$, 精度行列 (共分散行列 の逆行列) $S$ とする多次元正規分布を表す .

$$
\begin{aligned}
& \mathcal{N}\left(\boldsymbol{x} \mid \boldsymbol{\mu}, \boldsymbol{S}^{-1}\right)= \\
& \quad(2 \pi)^{-\frac{1}{2}}|\boldsymbol{S}|^{\frac{1}{2}} \exp \left\{-\frac{1}{2}(\boldsymbol{x}-\boldsymbol{\mu})^{T} \boldsymbol{S}(\boldsymbol{x}-\boldsymbol{\mu})\right\}
\end{aligned}
$$

$|\boldsymbol{S}|$ は行列式を表す .

また , 出力のノイズモデルを正規分布と仮定すると，入 カが与えられたもとでの第 $i$ モデルの出力の条件付き分 布は次式となる .

$$
p\left(y \mid \boldsymbol{x}, i, \theta_{i}\right)=\mathcal{N}\left(y \mid \boldsymbol{w}_{i}^{T} \boldsymbol{x}^{\prime}{ }_{n}, \beta_{i}^{-1}\right)
$$

以上より未知パラメータは以下となる .

$$
\left\{\left(\varphi_{i}, \boldsymbol{\mu}_{i}, \boldsymbol{S}_{i}, \boldsymbol{w}_{i}, \beta_{i}\right), i=1, \ldots, m\right\}
$$

今, $D=\left\{\left(\boldsymbol{x}_{n}, y_{n}\right)\right\}_{n=1}^{N}$ を観測学習データ集合とし， $Z=\left\{z_{i}^{n}\right\}_{i=1, n=1}^{m, N}$ を潜在変数集合とする . 但し, $z_{i}^{n}$ は入 力 $\boldsymbol{x}_{n}$ に対応する出力 $y_{n}$ が第 $i$ モデルから生成されたと

$* 2$ 本稿では, $f_{i}()$ はスカラ一関数とするが, 本稿の議論は全て ベクトル值関数の場合にも容易に拡張可能である.
する時 $1 て ゙$ 光れ以外は零をとるものとする .この時，完 全データの対数尤度関数は次式となる。

$$
\begin{aligned}
& p(D, Z \mid \Phi, \Theta, m)= \\
& \prod_{i=1}^{m} \prod_{n=1}^{N}\left\{\varphi_{i} \mathcal{N}\left(\boldsymbol{x}_{n} \mid \boldsymbol{\mu}_{i}, \boldsymbol{S}_{i}^{-1}\right) \mathcal{N}\left(y_{n} \mid \boldsymbol{w}_{i}^{T} \boldsymbol{x}_{n}^{\prime}, \beta_{i}^{-1}\right)\right\}^{z_{i}^{n}}
\end{aligned}
$$

ここで注意すべきは，上記尤度は，文献 [Waterhouse 95] と異なり， $i$ に関して積の形に分解可能である点である これにより全ての変分事後分布が各 $i$ 毎に独立に導出で きる.一方, 文献 [Waterhouse 95] ではゲート関数のパ ラメータが $i$ に関して分解できない為, 近似を余儀なく されていた.

\section{$5 \cdot 2$ MoE の変分ベイズ学習}

ベイズ学習では, 未知パラメータおよびモデル指標 $m$ はある事前分布を持つ確率変数として取り扱われる. 各 モデルの独立性を仮定すると全変数の結合分布は次式と なる .

$$
\begin{aligned}
& p(D, Z, \Phi, \Theta, m)=p(D, Z \mid \Phi, \Theta, m) p\left(\left\{\boldsymbol{\varphi}_{i}\right\}_{i=1}^{m} \mid m\right) \\
& \quad \times P(m)\left\{\prod_{i=1}^{m} p\left(\boldsymbol{\mu}_{i} \mid \boldsymbol{S}_{i}\right) p\left(\boldsymbol{\beta}_{i}\right) p\left(\boldsymbol{S}_{i}\right)\right. \\
& \left.\quad \times p\left(\boldsymbol{w}_{i} \mid\left\{\alpha_{i, j}\right\}_{j=1}^{d+1}, \boldsymbol{\beta}_{i}\right) \prod_{j=1}^{d+1} p\left(\alpha_{i, j}\right)\right\}
\end{aligned}
$$

式 (25) 中の未知パラメータの事前分布は自然共役事 前分布を用いた . 具体的には, $\left\{\varphi_{i}\right\}_{i=1}^{m}$ は Dirichlet 分 布, $\boldsymbol{\mu}_{i}, \boldsymbol{w}_{i}$ は正規分布, $\boldsymbol{S}_{i}$ は Wishart 分布とし,さら に $\beta_{i}, \alpha_{i, j}$ は Gamma 分布を仮定した . また , $m$ は一樣 分布とした。

$$
\begin{aligned}
& p\left(\{\varphi\}_{i=1}^{m} \mid m\right)=\mathcal{D}\left(\left\{\varphi_{i}\right\}_{i=1}^{m} \mid \delta_{0}\right) \propto \prod_{i=1}^{m} \varphi_{i}^{\delta_{0}-1} \\
& p\left(\boldsymbol{\mu}_{i} \mid \boldsymbol{S}_{i}\right)=\mathcal{N}\left(\boldsymbol{\mu}_{i} \mid \boldsymbol{\nu}_{0},\left(\xi_{0} \boldsymbol{S}_{i}\right)^{-1}\right) \\
& p\left(\boldsymbol{S}_{i}\right)=\mathcal{W}\left(\boldsymbol{S}_{i} \mid \eta_{0}, \boldsymbol{B}_{0}\right) \\
& \propto\left|\boldsymbol{S}_{i}\right|^{\frac{1}{2}\left(\eta_{0}-d-1\right)} \exp \left\{-\frac{1}{2} \operatorname{Tr}\left\{\boldsymbol{B}_{0} \boldsymbol{S}_{i}\right\}\right\} \\
& p\left(\boldsymbol{w}_{i} \mid \beta_{i},\left\{\alpha_{i, j}\right\}_{j=1}^{d+1}\right)=\mathcal{N}\left(\boldsymbol{w}_{i} \mid \mathbf{0},\left(\beta_{i} \Lambda_{i}\right)^{-1}\right) \\
& p\left(\beta_{i}\right)=\mathcal{G}\left(\beta_{i} \mid \rho_{0}, \lambda_{0}\right) \propto \beta_{i}^{\rho_{0}-1} e^{-\lambda_{0} \beta_{i}} \\
& p\left(\alpha_{i, j}\right)=\mathcal{G}\left(\alpha_{i, j} \mid \kappa_{0}, \zeta_{0}\right) \\
& P(m)=1 / M_{0}
\end{aligned}
$$

$\Lambda_{i}=\operatorname{diag}\left(\alpha_{i, 1}, \ldots, \alpha_{i, d+1}\right)$ である . また ，添字'0'のつ いた変数 (例えば $\delta_{0}$ ) は八イパーパラメータ (定数) を表 す. $\alpha_{i, j} \beta_{i}$ は $w_{i j}$ の精度 (分散の逆数) である.

变分事後分布 $Q$ は以下の分解形を仮定する.

$$
\begin{aligned}
Q= & Q(m) Q(Z \mid m) Q(\Phi \mid m) Q(\Theta \mid m) \\
=Q(m) Q(Z \mid m) Q\left(\left\{\varphi_{i}\right\}_{i=1}^{m} \mid m\right) Q(\boldsymbol{\mu} \mid m) Q(\boldsymbol{S} \mid m) & \\
& \times Q(\boldsymbol{w} \mid m) Q(\beta \mid m) Q(\boldsymbol{\alpha} \mid m)
\end{aligned}
$$


但し, $\boldsymbol{\varphi}=\left\{\varphi_{i}\right\}_{i=1}^{m}, \boldsymbol{\mu}=\left\{\boldsymbol{\mu}_{i}\right\}_{i=1}^{m}, \boldsymbol{S}=\left\{\boldsymbol{S}_{i}\right\}_{i=1}^{m}, \boldsymbol{W}=$ $\left\{\boldsymbol{w}_{i}\right\}_{i=1}^{m}, \boldsymbol{\alpha}=\left\{\alpha_{i j}\right\}_{i=1, j=1}^{m, d+1}, \boldsymbol{\beta}=\left\{\beta_{i}\right\}_{i=1}^{m}$ とする.

これらより,式 (14) の目的関数は以下の樣に具体化さ れる。

$$
\begin{aligned}
& \mathcal{F}_{m}=\left\langle\log \frac{p(D, Z \mid \Phi, \Theta, m)}{Q(Z \mid m)}\right\rangle_{Q(Z, \boldsymbol{\varphi}, \boldsymbol{\mu}, \boldsymbol{S}, \boldsymbol{W}, \boldsymbol{\beta} \mid m)} \\
& +\left\langle\log \frac{p(\boldsymbol{\varphi} \mid m)}{Q(\boldsymbol{\varphi} \mid m)}\right\rangle_{Q(\boldsymbol{\varphi} \mid m)}+\left\langle\log \frac{p(\boldsymbol{\mu} \mid \boldsymbol{S}, m)}{Q(\boldsymbol{\mu} \mid m)}\right\rangle_{Q(\boldsymbol{\mu}, \boldsymbol{S} \mid m)} \\
& +\left\langle\log \frac{p(\boldsymbol{S} \mid m)}{Q(\boldsymbol{S} \mid m)}\right\rangle_{Q(\boldsymbol{S}, \boldsymbol{B} \mid m)}+\left\langle\log \frac{p(\boldsymbol{W} \mid m)}{Q(\boldsymbol{W} \mid m)}\right\rangle_{Q(\boldsymbol{W}, \boldsymbol{\alpha} \mid m)} \\
& +\left\langle\log \frac{p(\boldsymbol{\alpha} \mid m)}{Q(\boldsymbol{\alpha} \mid m)}\right\rangle_{Q(\boldsymbol{\alpha} \mid m)}+\left\langle\log \frac{p(\boldsymbol{\beta} \mid m)}{Q(\boldsymbol{\beta} \mid m)}\right\rangle_{Q(\boldsymbol{\beta} \mid m)}
\end{aligned}
$$

\section{$5 \cdot 3$ 最適変分分布}

式 (8),(9) に従って最適変分事後分布を求めると以下 を得る. 本論文は, 変分ベイズ学習に基づく最適モデル 探索法の一般的枠組みの提案を主眼とし，MoEに対する 各変分事後分布の導出の詳細は論文の本質ではないので 紙面の都合上省略し, 読者が追試できる樣, 結果のみを 以下に整理しておく.

$$
\begin{aligned}
& Q\left(\left\{\varphi_{i}\right\}_{i=1}^{m} \mid m\right)=\mathcal{D}\left(\left\{\varphi_{i}\right\}_{i=1}^{m} \mid\left\{\delta_{0}+\bar{N}_{i}\right\}_{i=1}^{m}\right), \bar{N}_{i}=\sum_{n=1}^{N} \bar{z}_{i}^{n} . \\
& Q\left(\boldsymbol{\mu}_{i} \mid m\right)=\mathcal{T}\left(\boldsymbol{\mu}_{i} \mid \overline{\boldsymbol{\mu}}_{i}, \Sigma \boldsymbol{\mu}_{i}, f \boldsymbol{\mu}_{i}\right), \\
& \overline{\boldsymbol{\mu}}_{i}=\frac{\bar{N}_{i} \overline{\boldsymbol{x}}_{i}+\xi_{0} \boldsymbol{\mu}_{0}}{\bar{N}_{i}+\xi_{0}} \\
& \Sigma \boldsymbol{\mu}_{i}=\frac{1}{\bar{N}_{i}+\xi_{0}} f_{\boldsymbol{\mu}_{i}}^{-1} \boldsymbol{B}_{i} \\
& f \boldsymbol{\mu}_{i}=\bar{N}_{i}+\eta_{0}+1-d \\
& \boldsymbol{B}_{i}=\boldsymbol{B}_{0}+\sum_{n=1}^{N} \bar{z}_{i}^{n}\left(\boldsymbol{x}_{n}-\overline{\boldsymbol{x}}_{i}\right)\left(\boldsymbol{x}_{n}-\overline{\boldsymbol{x}}_{i}\right)^{T} \\
& \quad \bar{N}_{i}+\xi_{0}\left(\overline{\boldsymbol{x}}_{i}-\boldsymbol{\nu}_{0}\right)\left(\overline{\boldsymbol{x}}_{i}-\boldsymbol{\nu}_{0}\right)^{T} \\
& \bar{N}_{i} \xi_{0} \\
& \overline{\boldsymbol{x}}_{i}=\frac{1}{\bar{N}_{i}} \sum_{n=1}^{N} \bar{z}_{i}^{n} \boldsymbol{x}_{n} \\
& \mathcal{T}()
\end{aligned}
$$

ここに, $\mathcal{T}()$ は $d$ 次元 Student's-t-分布で次式で定義さ れる。

$$
\begin{aligned}
& \mathcal{T}(\boldsymbol{x} \mid \boldsymbol{\mu}, \Sigma, \nu)= \\
& \quad\left(1+\frac{1}{\nu} \operatorname{Tr}\left\{\Sigma^{-1}(\boldsymbol{x}-\boldsymbol{\mu})(\boldsymbol{x}-\boldsymbol{\mu})^{T}\right\}\right)^{-\frac{\nu+d}{2}}
\end{aligned}
$$

$\nu$ は自由度を表す．

$$
\begin{aligned}
Q\left(\boldsymbol{S}_{i} \mid m\right) & =\mathcal{W}\left(\boldsymbol{S}_{i} \mid \eta_{0}+\bar{N}_{i}, \boldsymbol{B}_{i}\right) \\
Q\left(\beta_{i} \mid m\right) & =\mathcal{G}\left(\beta_{i} \mid \rho_{0}+\frac{1}{2} \bar{N}_{i}, \lambda_{i}\right), \\
\lambda_{i} & =2 \lambda_{0}+\sum_{n=1}^{N} \bar{z}_{i}^{n}\left(y_{n}-\overline{\boldsymbol{w}}_{i}^{T} \boldsymbol{x}_{n}^{\prime}\right)^{2}+\overline{\boldsymbol{w}}_{i}^{T} \bar{\Lambda}_{i} \overline{\boldsymbol{w}}_{i}
\end{aligned}
$$

$$
\begin{gathered}
Q\left(\alpha_{i j} \mid m\right)=\mathcal{G}\left(\alpha_{i j} \mid \kappa, \zeta\right), \\
\kappa=\kappa_{0}+\frac{1}{2} \\
\zeta=\zeta_{0}+\frac{1}{2}\left\{\left(\Sigma \boldsymbol{w}_{i}\right)_{j j}+\left(\bar{w}_{i j}\right)^{2}\right\} \\
Q\left(\boldsymbol{w}_{i} \mid m\right)=\mathcal{T}\left(\boldsymbol{w}_{i} \mid \overline{\boldsymbol{w}}_{i}, \lambda_{i} f_{\boldsymbol{w}_{i}}^{-1} \Sigma \boldsymbol{w}_{i}, f \boldsymbol{w}_{i}\right), \\
f_{\boldsymbol{w}_{i}}=2 \rho_{0}+\bar{N}_{i}, \\
\overline{\boldsymbol{w}}_{i}=\Sigma \boldsymbol{w}_{i} \sum_{n=1}^{N} \bar{z}_{i}^{n} y_{n} \boldsymbol{x}_{n}^{\prime} \\
\Sigma \boldsymbol{w}_{i}=\left(\sum_{n=1}^{N} \bar{z}_{i}^{n}{\boldsymbol{x}^{\prime}}_{n} \boldsymbol{x}^{\prime}{ }_{n}+\bar{\Lambda}_{i}\right)^{-1} \\
\bar{\Lambda}_{i}=\operatorname{diag}\left(\bar{\alpha}_{i, 1}, \ldots, \bar{\alpha}_{i, d+1}\right)
\end{gathered}
$$

さらに ,

$$
\begin{aligned}
\bar{z}_{i}^{n}=Q\left(z_{i}^{n}=1 \mid m\right)=\frac{\exp \left\{\gamma_{i}^{n}\right\}}{\sum_{j=1}^{m} \exp \left\{\gamma_{j}^{n}\right\}} \\
\gamma_{i}^{n}=\Psi\left(\delta_{0}+\bar{N}_{i}\right)-\Psi\left(m \delta_{0}+\sum_{i=1}^{m} \bar{N}_{i}\right) \\
+\frac{1}{2} \sum_{k=1}^{d} \Psi\left(\eta_{0}+\bar{N}_{i}-\frac{k-1}{2}\right)-\log \left|\boldsymbol{B}_{i}\right| \\
-\frac{1}{2}\left(\bar{N}_{i}+\eta_{0}\right)\left\{\frac{1}{\bar{N}_{i}+\xi_{0}} f_{\boldsymbol{\mu}_{i}}^{-1}\right. \\
\left.+\operatorname{Tr}\left\{\boldsymbol{B}_{i}^{-1}\left(\boldsymbol{x}_{n}-\overline{\boldsymbol{\mu}}_{i}\right)\left(\boldsymbol{x}_{n}-\overline{\boldsymbol{\mu}}_{i}\right)^{T}\right\}\right\} \\
+\frac{1}{2} \Psi\left(\rho_{0}+\frac{\bar{N}_{i}}{2}\right)-\frac{1}{2} \log \lambda_{i} \\
-\frac{1}{2}\left\{\frac{1}{\lambda_{i}} f \boldsymbol{w}_{i}\left(y_{n}-\overline{\boldsymbol{w}}_{i}^{T} \boldsymbol{x}_{n}^{\prime}\right)^{2}\right. \\
\left.+\frac{f \boldsymbol{w}_{i}}{f \boldsymbol{w}_{i}-2} \boldsymbol{x}_{n}^{\prime T} \Sigma \boldsymbol{w}_{i} \boldsymbol{x}_{n}{ }_{n}\right\} .
\end{aligned}
$$

但し, $\Psi(x)$ は digamma 関数で次式で定義される.

$$
\Psi(x)=\frac{\partial \log \Gamma(x)}{\partial x}
$$

ここで， $\Gamma()$ は Gamma 関数を表す . 実際には, 以上を 式 (10),(11) に示した樣に反復式に書き換えて実行する ことになる

\section{$5 \cdot 4$ 事後予測分布}

アルゴリズムが収束し, 最適変分事後分布および得ら れれば，新たな入力 $\boldsymbol{x}_{N+1}$ に対する出力 $y_{N+1}$ の事後予 測分布は以下で算出される.

$$
\begin{aligned}
& p\left(y_{N+1} \mid \boldsymbol{x}_{N+1}, D\right)= \\
& \quad \int \sum_{i=1}^{m} G_{i}\left(\boldsymbol{x}_{N+1} \mid \Phi\right) \boldsymbol{w}_{i}^{T} \boldsymbol{x}_{N+1}^{\prime} Q(\Phi, \Theta \mid m) d \Phi d \Theta
\end{aligned}
$$


式 (26) は更に次式の樣に近似できる .

$$
\begin{aligned}
& p\left(y_{N+1} \mid \boldsymbol{x}_{N+1}, D\right) \simeq \\
& \sum_{i=1}^{m} \pi_{i} \mathcal{T}\left(y_{N+1} \mid \overline{\boldsymbol{w}}_{i}^{T} \boldsymbol{x}^{\prime}{ }_{N+1}, \lambda_{i} f_{\boldsymbol{w}_{i}}^{-1} V_{i, N+1}^{-1}, f \boldsymbol{w}_{i}\right)
\end{aligned}
$$

即ち, $y_{N+1}$ の事後予測分布は各要素分布が自由度 $f \boldsymbol{w}_{i}=$ $2 \rho_{0}+\bar{N}_{i}$ の Student- $t$ 分布から成る混合 Student- $t$ 分布 となる . 但し ,

$$
\begin{aligned}
\pi_{i} & =G_{i}\left(\boldsymbol{x} \mid \Phi^{\mathrm{MAP}}\right) \\
V_{i, N+1} & =1-\boldsymbol{x}^{\prime{ }_{N+1}}\left(\boldsymbol{x}^{\prime}{ }_{N+1} \boldsymbol{x}^{\prime T+1}+\Sigma_{\boldsymbol{w}_{i}}^{-1}\right)^{-1} \boldsymbol{x}^{\prime}{ }_{N+1}
\end{aligned}
$$

また， $\Phi^{\mathrm{MAP}}$ は $Q\left(\Phi \mid m^{*}\right)$ の MAP 推定値を表す . $y_{N+1}$ の平均および分散は以下の樣に得られる .

$$
\begin{aligned}
& \bar{y}_{N+1}=\sum_{i=1}^{m} \pi_{i} \overline{\boldsymbol{w}}_{i}^{T} \boldsymbol{x}^{\prime}{ }_{N+1} \\
& \sigma_{y_{N+1}}^{2}=\sum_{i=1}^{m} \frac{\pi_{i} \lambda_{i}}{f \boldsymbol{w}_{i}-2} V_{i, N+1}^{-1}
\end{aligned}
$$

\section{$5 \cdot 5$ 実 験 結 果}

[人エデータ]

提案アルゴリズムの挙動を可視化すべく，図 1(a) に示 す人工データを用いた.(明らかに，6 個の線形 expertによ る回帰が最適である ) 図 1 (b) に示す混合数 $m=6$ の初期 值に対し,従来の変分ベイズ学習を実行した結果を図 $1(\mathrm{c})$ に示す.尚 , 図中の直線は各 expert $\left(f_{i}, i=1, \ldots, m\right)$ を, 太い曲線は混合モデルによる予測曲線 $\bar{y}$, 両側の曲線 (点線) は $\bar{y} \pm \sigma_{y}$ を，各々示す.明らかに低品質の局所最 適解に収束している。

一方, 図 1(d) に示す樣に, 過少数のモデル $m=3$ か ら提案学習法を実行した結果, 混合数が $4,5,6$ と変化し ながら最終的に最適值 (図 1(h)) に収束した。但し，图 中のステップ数 $t$ は提案アルゴリズムの Step 4 て採録さ れなかった探索過程のステップ数は含まれていない事に 注意 .

図 1(f) は図 1(d) から (h) に至るまでの $\mathcal{F}_{m}$ 值, および 未学習データ (テストデータ) に対する 1 サンプルあたり の平均自乗誤差 (MSE) の值の推移を示したグラフであ る. 図 $1(\mathrm{e}),(\mathrm{f}),(\mathrm{g}),(\mathrm{h})$ の順に, $\mathcal{F}_{m}$ 值は $-41.5,-15.8$, $-1.6,1.2$ となり，より良いモデルに近づくにつれて $\mathcal{F}_{m}$ 值か増加していくこと，更に，MSE 值が关れに伴い確実 に減少していることが確認できる．

尚, 従来の変分ベイズ学習結果の図 $1(\mathrm{c})$ の $\mathcal{F}_{m}$ 值は -14.6 で $m=5$ の時の図 $1(\mathrm{~g})$ よりも下回っている. こ れは従来の変分ベイズ学習では局所最適性により最適な モデル探索が困難となり得ることを示している．

\section{[Delve データ]}

高次元データ (Delve データ [Rasmussen 96]) 中の "kin-8nm” データへの適用実験を行った .このデータは
Table 1: Fm and MSE values for each $\mathrm{m}$ and by the proposed model search (*).

\begin{tabular}{cc|ccccccc}
\hline \multicolumn{2}{c|}{$\mathrm{m}$} & 5 & 6 & 7 & 8 & 9 & 10 & $*$ \\
\hline \multirow{2}{*}{$\mathrm{F}_{\mathrm{m}}$} & $\min$ & -3002 & -2985 & -2911 & -2821 & -2969 & -2927 & $-\mathbf{2 4 0 1}$ \\
& $\max$ & -2671 & -2590 & -2587 & -2514 & -2567 & -2715 & $-\mathbf{2 3 8 1}$ \\
\hline \multirow{2}{*}{ MSE } & $\min$ & 0.481 & 0.498 & 0.476 & 0.465 & 0.475 & 0.480 & $\mathbf{0 . 4 5 7}$ \\
& $\max$ & 0.502 & 0.497 & 0.481 & 0.489 & 0.502 & 0.531 & $\mathbf{0 . 4 6 5}$ \\
\hline
\end{tabular}

8 リンクのロボットアームのフォワードキネマティックス のシミュレーションデータ (8 次元入力, 1 次元出力, 学 習, テストデータ数共 256 で, 高い非線形性と中程度の ノイズが含まれている) である .

表 1 の最後の闌を除く各闌は, 各 $m$ に対して従来の 変分ベイズ学習を異なる 10 通りの初期化で実行して得 られた $\mathcal{F}_{m}$ 値および MSE 值の平均値を示す . 明らかに， 局所最適性のために各 $m$ での $\mathcal{F}_{m}$ 值は大きくばらつい ており， $\mathcal{F}_{m}$ を用いた従来のバッチタイプのモデル選択 法では信頼性が低いと言える。

一方 , $m=5, \ldots, 10$ の各々を初期モデルとして提案モ デル探索学習法を独立に実行した . 各 $m$ について 1 回の みの実行にも関わらず全ての $m=5, \ldots, 10$ に対し，同 じ $m=8$ に収束した . 弚の時の $\mathcal{F}_{m}$ 值および MSE 值の 最大值，最小値を表 1 の最後の闌 ('*' が付記した欄) に 示す. 明らかに最大值と最小值の差が小さく安定した結 果が得られていることが分かる.また， 1 回の実行にも 関わらず, 提案学習法が最良の結果を得ていることも確 認できる .
6. ま
と
め

本論文では, 変分ベイズ学習の枠組みで, 非線形モデ ルの学習における局所最適性の問題とモデルの複雑さの 決定の問題を同時解決する学習法を提案し, 混合回帰モ デルへの適用実験により有効性を確認した，本論文で提 案したアルゴリズムは, 形式的には, 筆者らが先に提案 した SMEM アルゴリズムのベイズ拡張と見なせるが， SMEM アルゴリズムと異り，最良なモデル探索が実現で きるという点で大きく進展していると言える.現在，モ デルの複雑さの場合の数か指数オーダーとなる複雑な非 線形モデル (隠れマルコフモデル $(\mathrm{HMM}))$ への適用を進 めている．これについては別の機会に報告する．

\section{謝辞}

議論して頂いたロンドン大学 (Gatsby Computational Neuroscience Unit) の Dr. Zoubin Ghahramani に感 謝します。

\section{$\diamond$ 参 考 文 献 $\diamond$}

[Akaike 73] Akaike, H. : A new look at the statistical model identification, IEEE Trans. Autom. Contor., Vol.AC-19, pp.716-723 (1973). 


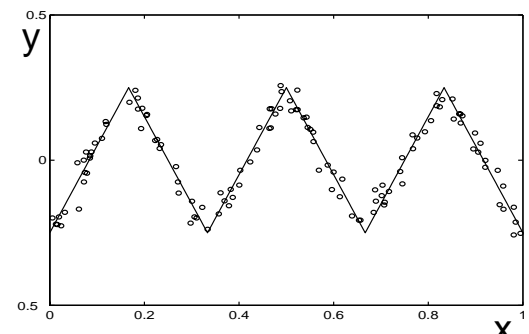

(a) True function and training data

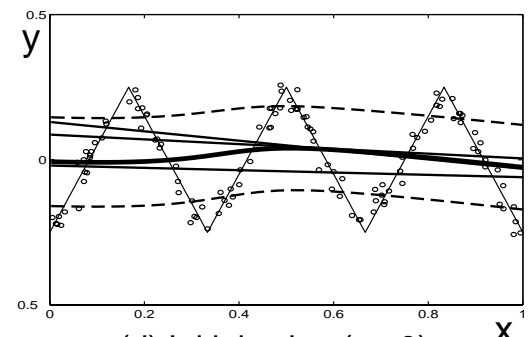

(d) Initial value $(m=3)$

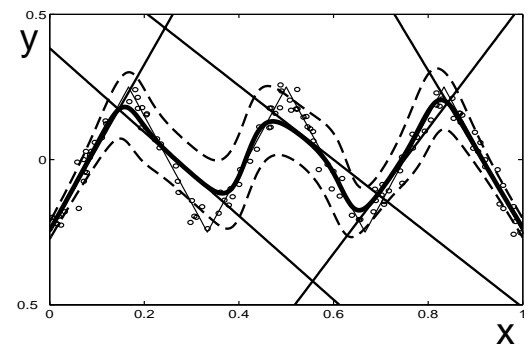

(g) $t=91$

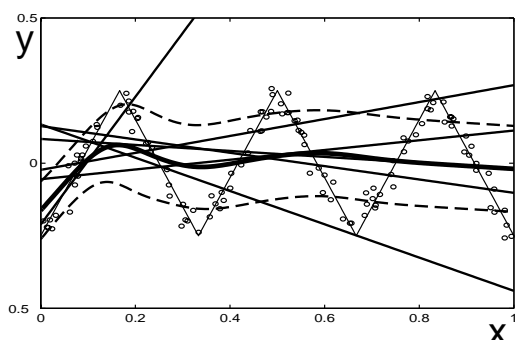

(b) Initial value $(\mathrm{m}=6)$

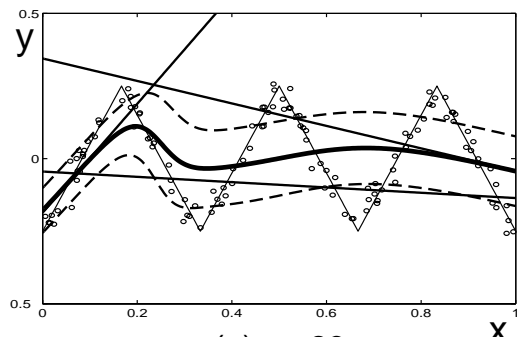

(e) $t=23$

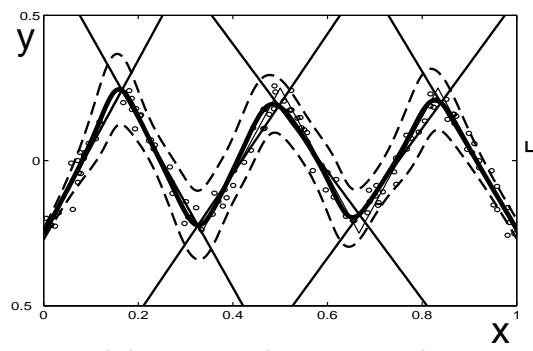

(h) $t=135$ (final result)

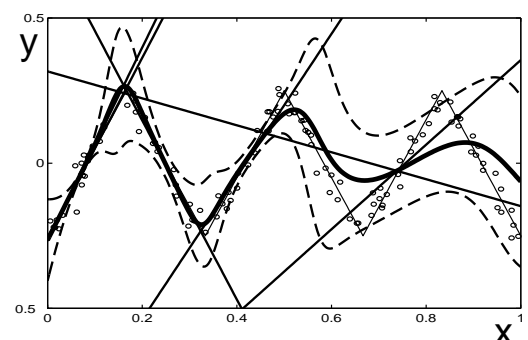

(c) Result by conventional VB $(m=6)$

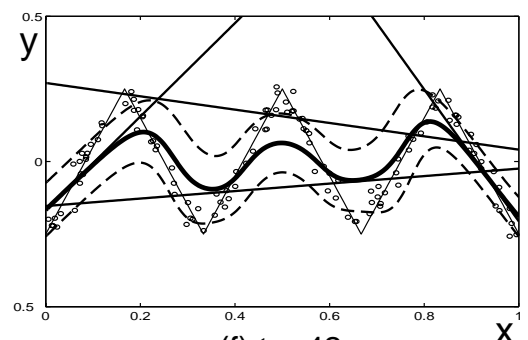

(f) $t=42$

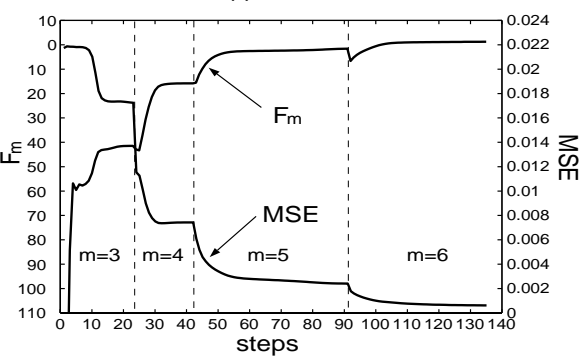

(i) Fm and MSE trajectories

図 $1 \mathrm{MoE}$ の学習結果 . (a) の人工データに対し, (b) の樣に最適混合数 $m=6$ で初期化しても従来の 変分ベイズ学習では (c) に示す樣に局所最適解に収束する.一方, 提案学習法では, (d) の過少 混合数 $m=3$ から探索を開始したところ分割操作を繰り返し, 最終的に (h) に示すような所望の 解に収束している. (i) は採用された探索過程における $\mathcal{F}_{m}, \mathrm{MSE}$ (テストデータに対する平均自 乗誤差) 值の推移を示す. $\mathcal{F}_{m}$ の増加に伴い MSE もほぼ単調に減少していることが確認できる .

[Attias 99] Attias, H. : Learning parameters and structure of latent variable models by variational Bayes, In proc. Uncertainty in Artificial Intelligence, (1999).

[Bartlett 96] Bartlett, P. : The sample complexity of pattern classification with neural networks: the size of the weights is more important than the size of the network, Technical report, Australian National University (1996).

[Dempster 77] Dempster, A.P., Laird, N.M., and Rubin, D.B. : Maximum likelihood from incomplete data via the EM algorithm, Journal of Royal Statistical Society B, Vol.9, pp.1-38 (1977).

[Gamerman 97] Gamerman, D. : Markov chain Monte Carlo, Chapman \& Hall (1997).

[Jacobs 91] Jacobs, R.J., Jordan, M.I. Nowlan, S.J., and Hinton, G.E. : Adaptive mixtures of local experts, Neural Computation, Vol.3, pp.79-87 (1991).

[Jordan 97] Jordan, M.I., Ghahramani, Z., Jaakkola, T.S., and Saul, L.K. : An introduction to variational methods for graphical models, Machine Learning, Vol.37, No.2 (1997).

[Richardson 97] Richardson, S. and Green, P. : On Bayesian analysis of mixtures with an unknown number of components, Journal of the Royal Statistical Society B, Vol.59, pp.731-792 (1997).

[MacKay 92] MacKay, D. : Bayesian interpolation, Neural Computation, Vol.4, pp.405-447 (1992).

[Rasmussen 96] Rasmussen, C.E., Neal, R.M., Hinton, G.E., van Camp, D., Revow, M., Ghahramani, Z., Kustra, R. and Tibshirani, R. : The DELVE Manual, http://www.cs.utoronto.ca/ delve/ (1996).

[Rissanen 87] Rissanen, J. : Stochastic complexity, Journal of the Royal Statistical Society B, Vol.49, pp.223-239 (1987).

[Saul 96] Saul, L.K., Jaakkola, T., and Jordan, M.I. : Mean field theory for sigmiod belief networks, Journal of Artificial Intelligence Research, Vol.4, pp.61-76 (1996).

[Ueda 99a] Ueda, N. and Nakano, R., Ghahramani, Z., and Hinton, G.E. : SMEM algorithm for mixture models, Advances in Neural Information Processing Systems 11 (1999).

[Ueda 99b] 上田, 中野 : 確率的混合部分空間法 -混合因子分析を 用いたパターン認識法-, 信学論, Vol.J82-D-II, No.12, pp.23942401 (1999).

[Ueda 00] Ueda, N. and Nakano, R., Ghahramani, Z., and Hinton, G.E. : SMEM algorithm for mixture models, Neural Computation, Vol.12, No.9, pp.2109-2128 (2000).

[Waterhouse 95] Waterhouse, S.R., MacKay, D. and Robinson, A.J. : Bayesian methods for mixture of experts, $A d$ vances in Neural Information Processing Systems 8, (1995).

[Xu 94] Xu, L., Jordan, M. I., and Hinton, G.E. : An alternative model for mixtures of experts, Advances in Neural Information Processing Systems 7, pp.633-640 (1994).

[Zoubin 00] Ghahramani, Z. and Beal, M.J. : Variational inference for Bayesian mixture of factor analyzers, Advances in Neural Information Processing Systems 12, (2000). 
〔担当委員 : 新田克己〕

2000 年 11 月 1 日 受理

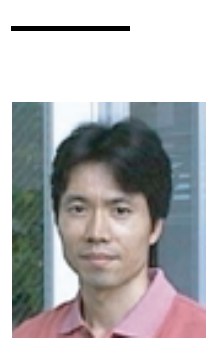

者 紹 介

上田 修功

1982 年大阪大学工学部通信工学科卒業. 1984 年同大学 院修士課程修了.同年 NTT 入社.1993-1994 年米国 Purdue 大学客員研究員 . 現在, NTT コミュニケーショ ン科学基整研究所 知能情報研究部創発学習研究グループ リーダ, 主幹研究員 (特別研究員), 奈良先端科学技術大学 院大学客員助教授 . 統計的学習理論の研究に従事 . 1992 年日本神経回路学会研究奨励賞, 1997 年電気通信普及財 団賞, 2000 年電子情報通信学会論文賞受賞 . 共著書 “わ かりやすいパターン認識 (オーム社)”など. 工学博士 . 電子情報通信学会 , 日本 神経回路学会, 日本統計学会, IEEE 各会員 